\title{
Two Cases of a Lieno-Mesenteric Trunk
}

\author{
By \\ Yoshimaru SUENAGA, Reiko NAKAMURA, KaORU INOUE, \\ Toshio TERASHIMA, Mitsuhiro TAKEDA \\ and YosHiro INOUE \\ Department of Anatomy, Hokkaido University School of Medicine, \\ Kita 15-jo, Nishi 7-chome, Kita-ku, Sapporo 060, Japan \\ -Received for Publication, January 26, 1982-
}

\begin{abstract}
Key words: Anomaly, Splenic artery, Superior mesenteric artery, Lieno-mesenteric trunk.

Summary: Two rare anomalous cases of the splenic artery arising from a common trunk with the superior mesenteric artery, which might be called a lieno-mesenteric trunk, were found in a 89 year-old female and 80-year old male among cadavers used for student dissection. In these cases, the celiac trunk was divided into two branches, the left gastric and the common hepatic arteries, forming a so called hepato-gastric trunk. Up to the present, this type of anomaly has been described in only 15 cases, as far as we can determine, including the present cases. The chief differences in the origin and the course of the splenic artery in both cases were as follows: the origin was on the left side of the lieno-mesenteric trunk in the first case, and at the anterior wall of the trunk in the second case. In the first case the splenic artery ran at the level of the margin of the greater curvature of the stomach, whereas in the second case it was behind the body of the stomach. There was no remarkable variation in the pattern and distribution of the branches arising from the splenic artery. These cases were not classified by Adachi, but belong to type IV'" described by Morita.
\end{abstract}

Two rare varitions of the splenic artery in which the splenic artery arose from a common trunk with the superior mesenteric artery, were observed in cadavers used for student dissection in 1978 and 1980. This type of variation has been reported in only 13 cases in the world as far as we can determine.

In the present study, we intend to report our cases of this type of anomaly.

\section{Observations and Discussion}

I. The first case (Figs. $1 \mathrm{~A}$ and $\mathrm{B}$ ): $\mathrm{Fe}$ male, 89 years-old. In this subject, the main branches directly arising from the abdominal aorta and distributed to the digestive organs were three; the common trunk of the hepatic and left gastric arteries (the hepato-gastric trunk), the common trunk of the splenic and superior mesenteric arteries (the lieno-mesenteric trunk), and the inferior mesenteric artery. The inferior mesenteric artery ran in a 
usual course as described in many monographs. In this case the duplicated inferior vena cava was also recognized as other than the lieno-mesenteric trunk mentioned above (CID and CIS). The outline and the course of these arteries in this case were as follows:

A) The hepato-gastric trunk (THG).

The hepato-gastric trunk, in which the common hepatic artery (HC) had a common origin with the left gastric artery (GS), originated from the front of the abdominal aorta at the level of the 12 th thoracic vertebra. The left gastric artery gave off the cardio-esophageal branch (CE) as described by Michels (1955) and then descended along the margin of the lesser curvature of the stomach. The common hepatic artery gave off the right gastric artery (GD) and then divided into two branches; the proper hepatic artery and the gastroduodenal artery. The proper hepatic artery gave off three branches at the liver; a left, intermediate, and right branch. The two cystic arteries arose from the right branch. The gastroduodenal artery gave off the anterior and posterior superior pancreaticoduodenal arteries (PDSA and PDSP). The anterior supeior pancreaticoduodenal artery joined the posterior inferior pancreaticoduodenal artery (PDIP), which directly arose from the superior mesenteric artery (MS), whereas the posterior superior pancreaticoduodenal artery joined the anterior inferior pancreaticoduodenal artery (PDIA), which arose from the middle colic artery (CM). Thus two arches of the pancreatic arteries seemed to twist each other within the pancreas.

B) The lieno-mesenteric trunk (TLM).

The lieno-mesenteric trunk, in which the splenic artery had a common origin with the superior mesenteric artery, orgiinated from the front of the abdominal aorta at the level of the first lumbar vertebra. The splenic artery arose from the left side about $40 \mathrm{~mm}$ distal to the origin from the aorta. The splenic artery transversally passed to the spleen near the margin of the greater curvature of the stomach. Its length was measured at about $110 \mathrm{~mm}$. The short gastric and left gastroepiploic arteries arose at the distal portion of the splenic artery.

II. The second case (Figs. 2A and $\mathrm{B}$ ): Male, 80 years-old. In this subject, the main branches originated directly from the abdominal aorta and distributed to the digestive organ were similar to the first case. They were the hepato-gastric and the lieno-mesenteric trunks and the inferior mesenteric artery. No remarkable variation of the inferior mesenteric artery was seen in a running course and distribution. The outline and the course of these arteries were as follows:

A) The hepato-gastric trunk (THG).

This trunk arose from the front of the abdominal aorta at the level of the 12 th thoracic vertebra. The trunk gave off the right and left inferior phrenic arteies, and the left gastric artery at almost the same level about $9 \mathrm{~mm}$ distal to its origin from the aorta, and then passed to the liver as the common hepatic artey. Both the inferior phrenic arteries gave off right and left suprarenal arteries running to the suprarenal glands on both sides respectively and then distributed to the diaphragma as terminal branches. The left gastric artery passed in a usual course to the lessr curvature of the stomach. The common hepatic artery divided into the proper hepatic and gastroduodenal arteries. The right gastric artery arose from the proper hepatic artery near its origin. The posterior superior pancreaticoduodenal artery gave off the transversal pancreatic artery which joined the splenic artery through the dorsal pancreatic artery. The anterior and the posterior superior pancreaticoduodenal arteries anastomosed with the inferior 
pancreaticoduodenal arteries originating from the right side of the superior mesenteric artery.

B) The lieno-mesenteric trunk (TLM).

This trunk arose from the front of the abdominal aorta at the level of the first lumbar vertebra, and then divided into the superior mesenteric artery and the splenic artery about $28 \mathrm{~mm}$ distal to its origin. The superior mesenteric artery ran in a common manner. The splenic artry arose from the front of this trunk, sharply turned to the left and then ran transversely at the back of the body of the stomach, and was located superior to the pancreas. The total length of the splenic artery was measured at about $127 \mathrm{~mm}$. The terminal branches of the splenic artery were four in number; the superior polar, superior, inferior and inferior polar arteries. The short gastric artries arose from the superior polar artery and the left gastro-epiploic artery arose from the inferior polar artery. The dorsal pancreatic artery arose from the splenic artery near its origin and anastomosed with the transversal pancreatic artery (PT).

The celiac trunk and superior mesenteric artery revealed various patterns in their branching and distribution, and further in connection between the two (Eaton, 1917; Adachi, 1928; Tsukamoto 1929; Morita, 1935; and Michels, 1955). Adachi (1928) investigated these arteries in about 252 cadavers and grouped them into 6 types or 28 groups. However, this type of lieno-mesenteric trunk was not observed. As far as we can determine, up to the present 13 cases of lieno-mesenteric trunk have been reported by Rossi and Cova (1904), Bergmann (1933), Morita (1936), Ishii (1953), Clausen (1955), Michels (1955), Kato et al. (1974), Katsume et al. (1979), Kou et al. (1980) and Hayashi et al. (1981) as revealed in Table I.

In this paper, the description of the
Table 1. Case reports of the Lieno-mesenteric Trunk.

\begin{tabular}{l|c}
\hline \multicolumn{1}{c|}{ Authers (year) } & Cases \\
\hline Rossi \& Cova (1904) & 2 \\
Bergman (1933) & 1 \\
Morita (1936) & 2 \\
Ishii (1953) & 1 \\
Clausen (1955) & 1 \\
Michels (1955) & 2 \\
Kato et al. (1974) & 1 \\
Katsume et al. (1979) & 1 \\
Kou et al. (1980) & 1 \\
Hayashi et al. (1981) & 1 \\
Suenaga et al. (1982) & 2 \\
\hline Total & 15 \\
\hline
\end{tabular}

first case is regrettably insufficient, because the dissection had significantly proceeded when we found the anomaly, but the second case was thoroughly observed. Some findings from the first case are compared with those of the second (Table 2). The origin and the course of the splenic artery were noticeably different in these two cases. The origin was at the left side of the lieno-mesenteric trunk in the first case and in front of the trunk in the second. In the first case, the splenic artery ran at the level near the margin of the greater curvature of stomach, whereas in the second it was behind the body of the stomach.

The reason why this type of vascular anomaly rarely occurs has only been explained by Tandler (1904) and Morita (1936) on the basis of the morphogenesis of the omphalo-mesenteric arteries. Their theories seem to be insufficient, because the relationship between the development of the spleen and the morphogenesis of the lieno-mesenteric trunk is not clear. Their relationship should be further studied. 
Table 2. Comparison between the present two cases of the lieno-mesenteric trunk.

\begin{tabular}{|c|c|c|}
\hline & First case & Second case \\
\hline 1. Hepato-gastric trunk & formed & formed \\
\hline 2. Lieno-mesenteric trunk & formed & formed \\
\hline $\begin{array}{l}\text { 3. Height of the origin of } \\
\text { the trunk from the aorta }\end{array}$ & the first lumbar vertebra & the first lumbar vertebra \\
\hline $\begin{array}{l}\text { 4. Origin of splenic artery } \\
\text { from the trunk }\end{array}$ & at the left side of the trunk & in front of the trunk \\
\hline 5. Length of the trunk & $40 \mathrm{~mm}$ & $28 \mathrm{~mm}$ \\
\hline $\begin{array}{l}\text { 6. Course of the splenic } \\
\text { artery }\end{array}$ & $\begin{array}{l}\text { near the margin of the } \\
\text { greater curvature }\end{array}$ & $\begin{array}{l}\text { behind the body of the } \\
\text { stomach }\end{array}$ \\
\hline $\begin{array}{l}\text { 7. Length of the splenic } \\
\text { artery }\end{array}$ & $110 \mathrm{~mm}$ & $127 \mathrm{~mm}$ \\
\hline $\begin{array}{l}\text { 8. Other marked anomaly } \\
\text { in vascular system }\end{array}$ & $\begin{array}{l}\text { duplicated vena cava } \\
\text { inferior }\end{array}$ & not observed \\
\hline
\end{tabular}

\section{References}

1) Adachi, B.: Das Arteriensystem der Japaner. Bd. II, Tokyo, Kenkyusha Press, 64-68, 1928.

2) Aso, S.: Über das Gefässystem des Rumpfes bei der japanischen Föten II. Das Arteriensystem. Acta Anat. Nippon, 5: 41-77, 1933. (in Japanese)

3) Bergmann, L.: Über einige seltene Anomalien der A. coeliaca. Zeites. Anat. u. Entw., BD. 101, 525-533, 1933.

4) Clausen, H.J.: An unusual variation in origin of the hepatic and splenic arteries. Anat. Rec., 123: 335-340, 1955.

5) Eaton, P.B.: The coeliac axis. Anat. Rec., 13: 369-374, 1917.

6) Hayashi, K., S. Shoumura, N. Ishizaki, S. Emura, T. Yamahira and H. Isono: A rare anomalous case of the splenic artery. Acta Anat. Nippon, 56: 481-483, 1981.

7) Ishii, T.: Ein abnormer Fall von Ursprung und Astverteilung der A. lienalis. Acta Anat. Nippon, 28-89, 1953.

8) Katsume, Y., M. Yoshizuka, K. Sasaki, A. Hirotsu, T. Ariyoshi and J. Saruwatari : A very rare anomalous case of the splenic artery. J. Kur. M. A., 42: 286-288, 1979.

9) Kato, S. and S. Morita: Corrosions anatomical studies on the arterial system of the Japanese fetus. VII. The branches of the abdominal aorta (abstract). Acta Anat. Nippon, $49: 79$, 1974. (in Japanese)

10) Kou, S., A. Takemura, T. Irifune and $T$. Irifune: A case of the Splenic Artery arising from the superior mesenteric artery. Okajimas Folia Anat. Jpn. Bd. 57, Heft $4: 241-250,1980$.

11) Michels, M.: Blood supply and anatomy of the upper abdominal organs. Lippincott., Philadelphia, 1955.

12) Morita, M.: Reports and conception of three anomalous cases on the celiac and the superior mesenteric arterie's area. Igaku Kenkyu (Acta med.), 9: 159-172, 1935.

13) Morita, M.: Three cases with variations of the celiac artery. (Supplement), Igaku Kenkyu (Acta med.), 10:107-112, 1936.

14) Rossi, G. and E. Cova : Studio morfologico delle arterie dello stomaco. Arch. ital. anat. e embriol., 3 : 485-524, 566-657, 1904. Cited from KOU (1980).

15) Tandler, J.: Zur entwickelungsgeschichte der menschlicher Darmarterien. Anat. Hefte., 23 : 187-209, 1903.

16) Tandler, J.: Über die Varietäten der Arteria coeliaca und deren Entwickelung. Anat. Hefte., 25 : 475-500, 1904.

17) Tsukamoto, N.: Studies on the arterial system in the abdominal cavity of the Japanese. Acta Anat. Nippon, 2: 780820, 1929. (in Japanese) 


\section{PLATES}




\section{Explanation of Figures}

CE : Rr. cardio-esophagei

CID : V. cava inferior dextra

CIS : V. cava inferior sinistra

CM: A. coliaca media

CY: A. cystica

GD: A. gastrica dextra

GS: A. gastrica sinistra

GDU: A. gastroduodenalis

GED : A. gastroepiploica dextra

GES: A. gastroepiploica sinistra

GV: Aa. gastricae breves

$\mathrm{HC}$ : A. hepatica communis

HP : A. hepatica propria

HD : R. hepatica dextra

HM : R. hepatica media

HS : R. hepatica sinistra

L: A. lienalis

\section{Key to Abbreviation}

MS : A. mesenterica superior

PD : A. pancreatica dorsalis

PT: A, pancreatica transversa

PDSA: A. pancreaticoduodenalis superior anterior

PDI : A. pancreticoduodenalis inferior

PDSP: A. pancreaticoduodenalis superior posterior

PDIA : A. pancreaticoduodenalis inferior

PDIP: A. pancreaticoduodenalis inferior posterior

PID: A. phrenica inferior dextra

PIS: A. phrenica inferior sinistra

SRD: Glandula suprarenalis dextra

SRS: Glandula suprarenalis sinistra

THG: Truncus hepatogastricus

TLM : Truncus lienomesentericus

\section{Plate I}

Fig. 1A: A ventral view of the first anomaly case. The lieno-mesenteric trunk (TLM) and the duplicated inferior vena cava (CID and CIS) are shown. The splenic artery (L) arises from the left side of the trunk.

Fig. 1B: A semi-schematic drawing of Fig. 1A. The terminal branches of the hepato-gastric (THG) and the lieno-mesenteric trunk (TLM) are shown in detail. The splenic artery runs transversally to the spleen at the height of the greater curvature of the stomach. 


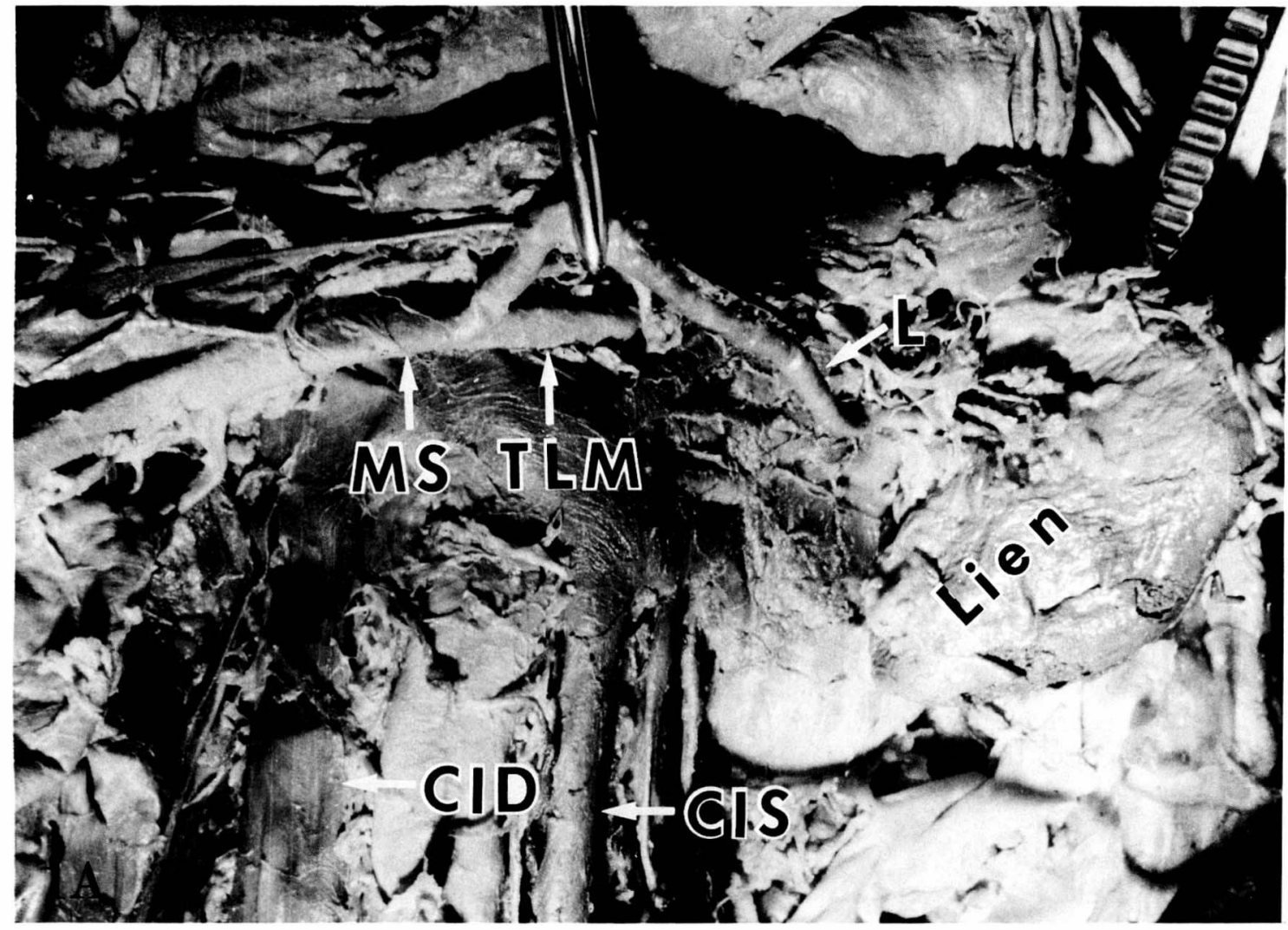

Truncus lieno-mesentericus ( $T L M$ ) and truncus hepato-gastricus(THG)

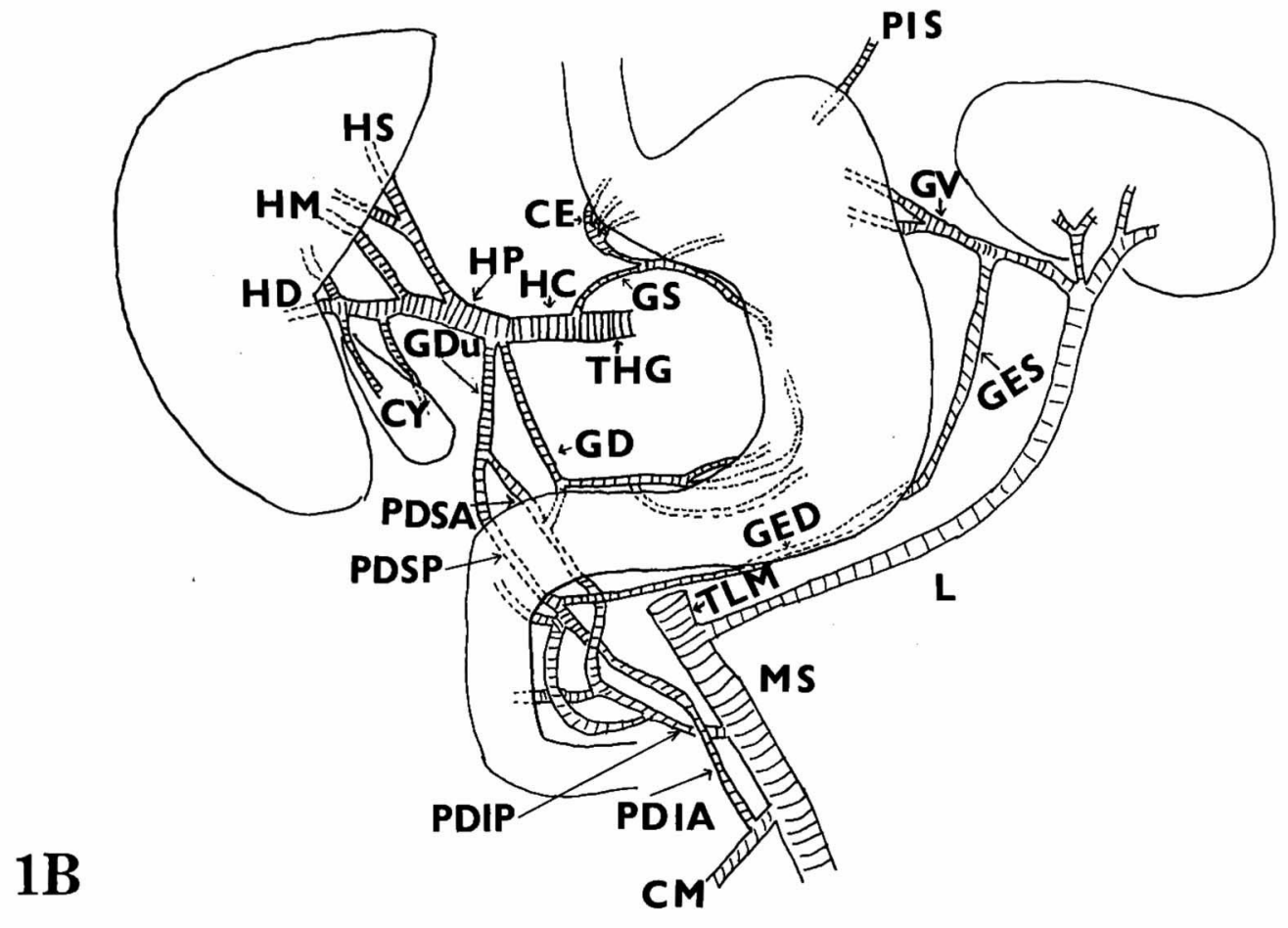

Y. Suenaga, et al. 


\section{Plate II}

Fig. 2A: A ventral view of the second anomaly case. The hepato-gastric (THG) and the lieno-mesenteric trunk (TLM) are shown. The splenic artery (L) arises from the anterior wall of the trunk and then turns sharply to the left to the spleen.

Fig. 2B: A semi-schematic drawing of Fig. 2A. The terminal branches of the hepato-gastric (THG) and the lieno-mesenteric trunk (TLM) are shown in detail. The splenic artery runs to the spleen behind the body of the stomach. The arteries distributing to the pancreas are clearly observed in this case. The dorsal pancreatic artery (PD) arises at the origin of the splenic artery and joins the transversal pancreatic artery (PT). 
Plate II

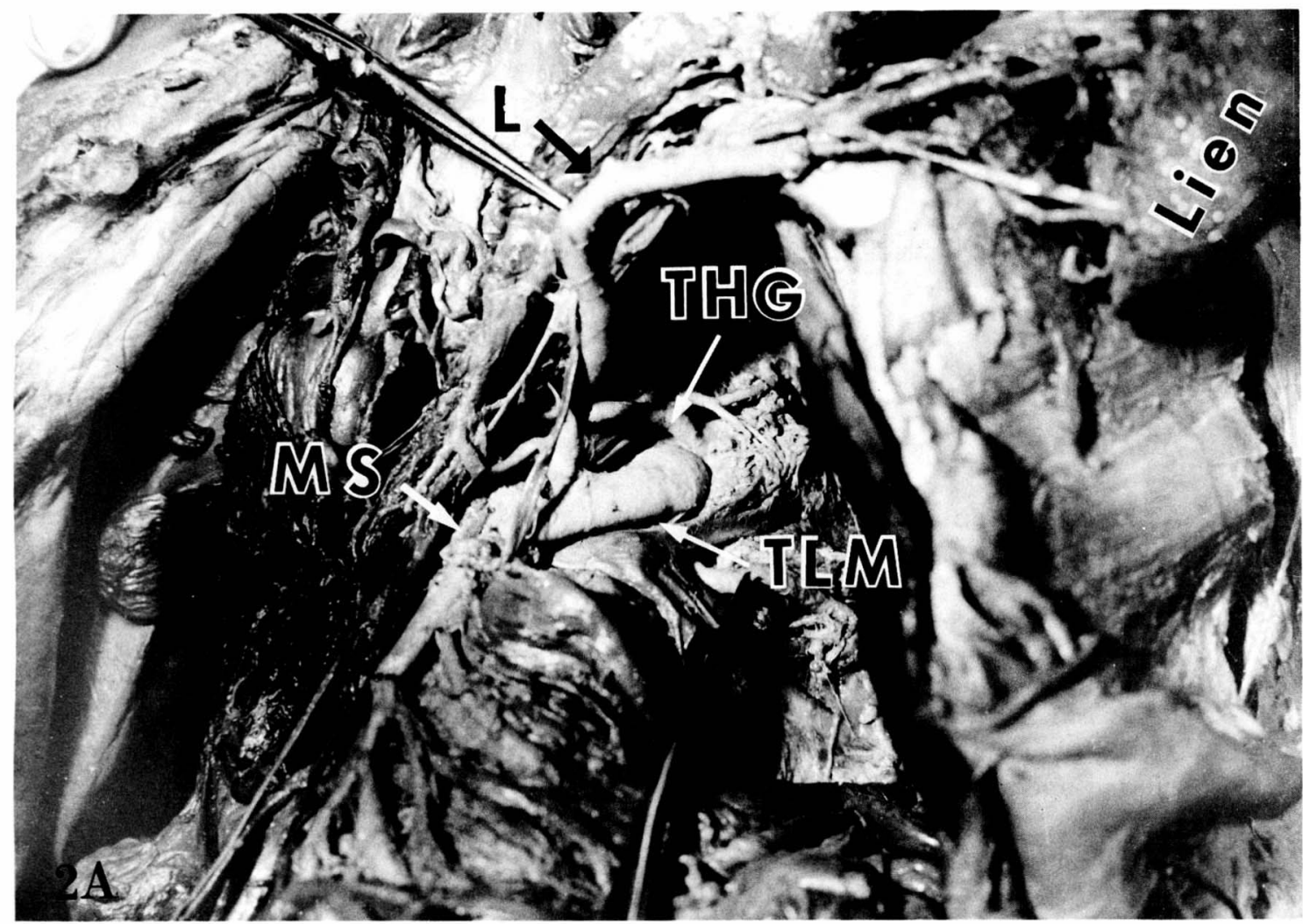

Truncus lieno-mesentericus (TLM) and truncus hepato-gastricus(THG)

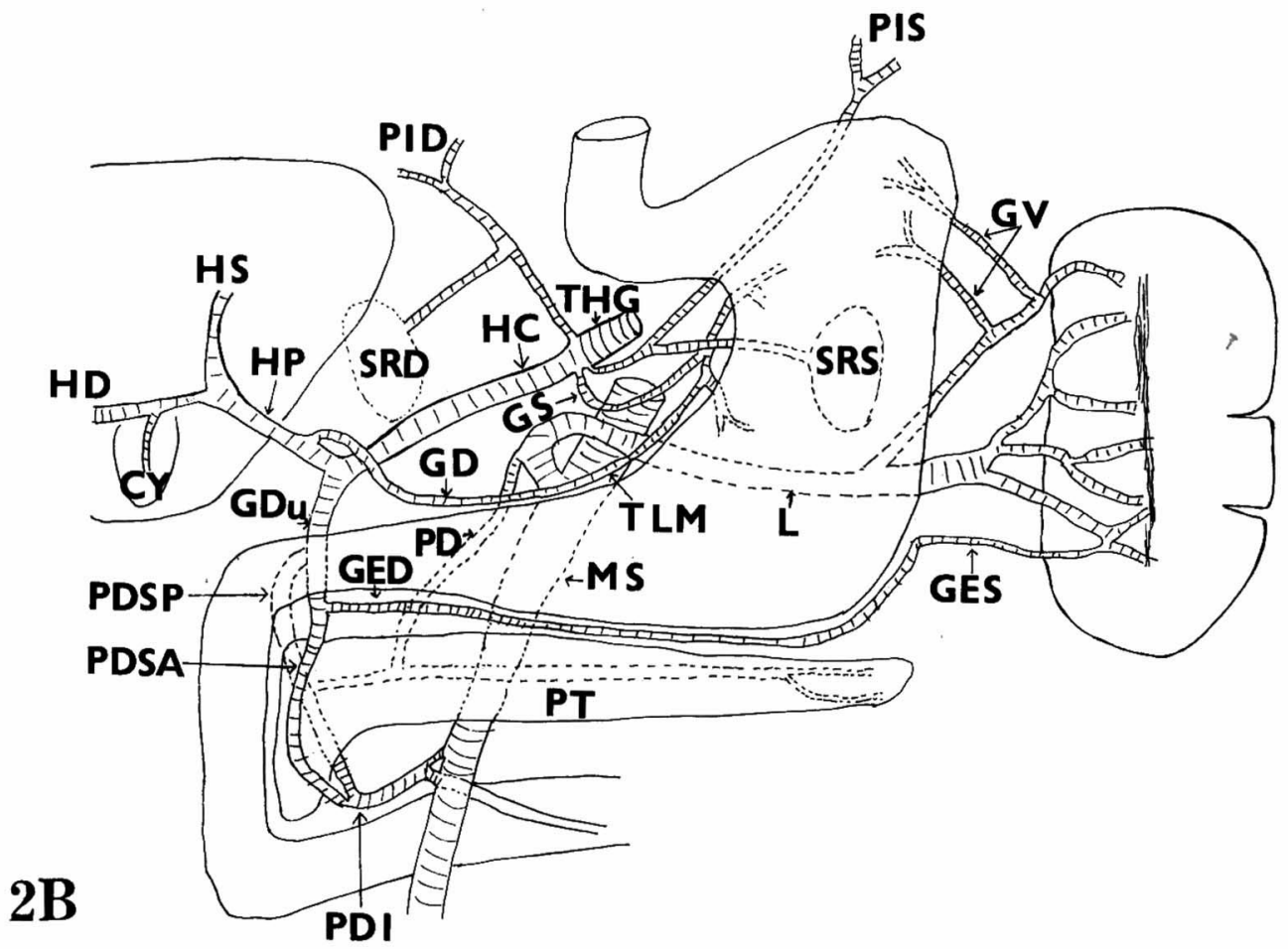

Y. Suenaga, et al. 